\title{
Reputed dentists and / or specialists in the oro-maxillo-facial field who worked in French civil and military hospitals during the First World War (1914-1918)
}

\author{
Reputați medici stomatologi și/sau cu specialități din \\ sfera oro-maxilo-facială care au activat în spitalele franceze civile și militare \\ în timpul primului război mondial (1914-1918)
}
Liliana Moraru1, Viorel Ștefan Perieanu², Mihai Burlibașa², Claudia-Camelia Burcea², Mădălina Violeta Perieanu², Mădălina Adriana Malița², Irina-Adriana Beuran², Mihai David², Oana Eftene ${ }^{2}$, Mihaela Chirilă2 ${ }^{2}$ Ioana-Cristina Neagoe ${ }^{3}$, Magdalena Natalia Dina², Ioana Voinescu², Elena Rabolu³, Valentin Daniel Sîrbu², Corina Marilena Cristache ${ }^{3}$
${ }^{1}$ Universitatea „Titu Maiorescu“, București, România
¿Universitatea de Medicină și Farmacie „Carol Davila“, București, România
3Universitatea „Dacia“, Pitești, România

\begin{abstract}
The First World War was and is considered the most terrible conflagration of all time. Thus, over $65,000,000$ soldiers made up the corps of land armies, naval and air forces, combat armies that participated in the conduct of military operations during the First World War. About 8,500,000 people died and more than 21,000,000 were injured. France was one of the countries most affected by this war, its medical services, including dentistry and oral and maxillofacial surgery, being completely obsolete. Thus, in this material, we tried to describe some important figures of French oral and maxillofacial dentistry and surgery, which were active in French civil and military hospitals during the First World War (1914-1918).
\end{abstract}

Keywords: World War I, dentists, oral and maxillofacial surgery

\section{REZUMAT}

Primul război mondial a fost și este considerată cea mai cumplită conflagrație din toate timpurile. Astfel, peste 65.000.000 de soldaţi au alcătuit corpul armatelor terestre, forţelor navale şi aeriene, armate combatante care au participat la desfășurarea operațiunilor militare din timpul primului război mondial. în jur de 8.500 .000 de oameni au murit şi peste 21.000 .000 au fost răniţi. Franța a fost una dintre țările cele mai afectate de acest război, serviciile sale medicale, inclusiv cele de stomatologie și de chirurgie buco-maxilo-facială fiind depășite în totalitate. Astfel, în acest material, am încercat să descriem câteva figuri importante ale stomatologiei și chirurgiei buco-maxilo-faciale franceze, care au activat în spitalele franceze civile și militare în timpul primului război mondial (1914-1918).

Cuvinte cheie: primul război mondial, medici stomatologi, chirurgie buco-maxilo-facială

\section{INTRODUCERE}

Primul război mondial a fost probabil cea mai nimicitoare înfruntare a tuturor timpurilor. Astfel, peste 25 de ţări au luat parte la acest uriaș conflict, fie de partea Antantei, fie de cea a Puterilor Centrale.

Printre marile Puteri Aliate (Antanta), victorioase în cele din urmă, s-au numărat Franţa, Marea Britanie, Rusia, Italia, Japonia şi, din anul 1917, 
Statele Unite ale Americii. Nucleul Puterilor Centrale a fost constituit din Prusia (Imperiul Prusac), Imperiul Austro-Ungar (Austro-Ungaria) şi Imperiul Otoman (Turcia) $(1,2,3)$.

Concret, primul război mondial a dus la prăbuşirea a patru mari dinastii imperiale, în Germania, Rusia, Austro-Ungaria şi Turcia. A fost cauza Revoluţiei Ruse din anul 1917, a destabilizat Europa şi a sădit germenii celui de-al doilea război mondial (1939-1945) (1,2,3).

În timpul primului război mondial, Franța a fost una dintre cele mai afectate țări de pe urma conflagrației mondiale. Până în ziua armistițiului (11 noiembrie 1918), circa 1,6 milioane de francezi au fost uciși, iar alte patru milioane au fost răniţi $(4,5)$. În plus, mai multe regiuni ale țării au suferit de pe urma ocupației germane și a devastărilor cauzate de lupte.

Asupra Serviciilor Medicale Franceze, atât civile, cât și militare, presiunea acestor confruntări desfășurate pe teritoriul national a fost cu adevărat fantastică. Tot ceea ce a însemnat practician cu o pregătire medicală mai mult sau mai puțin aprofundată (medici, asistenți medicali, infirmieri etc.) a fost implicat în îngrijirea răniților de pe fronturile unde trupele franceze efectiv luptau contra armatelor Puterilor Centrale. Tot în această categorie a personalului medical, au intrat și cei care practicau medicina dentară: medici stomatologi, asistenți medicali de stomatologie, tehnicieni dentari. Astfel, în acest material vom încerca să descriem câteva figuri importante ale stomatologiei și chirurgiei buco-maxilo-faciale franceze care au activat în spitalele franceze civile și militare în timpul primului război mondial (1914-1918) $(4,5)$.

\section{GEORGES VILLAIN (1881-1938)}

A fost o personalitate remarcabilă a medicinei dentare franceze, profesor în cadrul Școlii de Medicină Dentară (devenită ulterior Facultatea de Medicină Dentară) din Paris, a cărui intensă activitate în timpul primului război mondial (19141918), atât clinică, cât și de organizare, a condus la definirea statutului medicilor stomatologi și al tehnicienilor dentari în cadrul armatei franceze (6-11).

Marele dentist francez s-a născut pe 31 mai 1881 în Paris. Provenit dintr-o familie foarte modestă, tânărul Georges s-a alăturat, foarte tânăr fiind, în calitate de ucenic al lui Georges Viau, un experimentat dentist parizian din acea vreme (6-11). După finalizarea uceniciei în cabinetul Dr. Viau, Georges Villain a plecat în Anglia pentru a-și continua studiile în medicină dentară, alăturându-se unui renumit medic stomatolog londonez, care i-a și fost tutore pe toată perioada șederii în Londra (6-11). Cu această ocazie, Dr. Villain a dobândit nu doar cunoștințe solide de stomatologie, dar a învățat şi să vorbească fluent limba engleză, lucru care avea să îi fie extrem de folositor în anii care au urmat.

În anul 1902, Villain s-a reîntors în oraşul natal, Paris, și s-a angajat în cadrul deja consacratei Școli de Medicină Dentară din acest oraș, un an mai târziu, în anul 1904, obținând și diploma de chirurgdentist în cadrul acestei prestigioase instituții franceze de învățământ medical (6-11).

Astfel, în anul 1902, îl găsim pe George Villain preparator de ortodonție și ortopedie dento-facială în cadrul Școlii de Medicină Dentară din Paris, devenind în anul 1904 demonstrator calificat în cadrul aceleiași unități de învățământ de stomatologie pariziene (6-11).

În anul 1905, Charles Godon (1854-1923), cel care a înființat Școala de Medicină Dentară din Paris, a decis să îl trimită pe tânărul Georges Villain în Statele Unite ale Americii, pentru a-și continua studiile. Concret, acesta s-a înscris în cadrul Facultății de Stomatologie a Universității din Pennsylvania (University of Pennsylvania Faculty of Dentistry), obținând diploma universitară de chirurg-dentist (DDS - Doctor of Dental Surgery) în anul 1906. La revenirea sa în Paris, Dr. Georges Villain a devenit asistentul Dr. Isaac Davenport, un experimentat medic dentist american stabilit de ceva vreme în capitala franceză și care activa deja în calitate de cadru didactic în cadrul Școlii de Medicină Dentară din Paris (6-11).

În continuare, cariera marelui Georges Villain a fost una cu adevărat remarcabilă și poate fi sintetizată astfel:

- în anul 1907, a devenit prin concurs șeful Clinicii de Protetică Dentară, din cadrul Școlii de Medicină Dentară din Paris;

- în anul 1908, a susținut concursul pentru ocuparea postului de profesor de protetică dentară fixă și ortodonție, în cadrul aceleiași instituții de învățământ de medicină dentară pariziene, obținând numirea și titularizarea definitivă pe acest post în anul 1909, rămânâd în această poziție până la sfârșitul vieții. Profesorul Georges Villain a fost nu doar un excelent practician, ci și un teoretician desăvârșit;

- totodată, în anul 1907, marele maestru dentist francez a intrat și în consiliul de administrație al Școlii de Medicină Dentară din Paris, fiind seceretar general al acestei im- 
portante instituții medicale franceze, între anii 1910 şi 1919;

- în anul 1920, Profesorul Georges Villain a devenit director adjunct al Școlii de Medicină Dentară din Paris, post pe care 1-a deținut până în anul 1926;

- în anul 1926, Profesorul George Villain a devenit director plin al Şcolii de Medicină Dentară din Paris, post pe care 1-a deținut până la moartea sa, în anul 1938 (6-11).

Concret, Profesorul Georges Villain a devenit succesorul lui Charles Godon (1854-1923), fondatorul Școlii de Medicină Dentară din Paris. Totodată, reputatul medic dentist francez a fost şi autor sau coautor a numeroase materiale științifice de o valoare incontestabilă, fiind vicepreședinte în anul 1913 și apoi președinte în anul 1920 al Societății de Odontologie din Paris (Société Odotologique de Paris), una dintre cele mai importante asociații științifice şi profesionale din Europa din acea perioadă (6-11).

Trebuie amintit și faptul că, tot în anul 1920, Profesorul Georges Villain a fost și vicepreședinte al Secțiunii de Odontologie al Asociației Franceze pentru Progresul Științei, post pe care 1-a deținut până în anul 1921. În anul 1932, același Prof. Villain a devenit și președinte al Societății Europene de Ortodonție (6-11).

Timp de peste trei decenii a fost membru în comitetul știinţific al prestigioasei reviste franceze L'Odontologie și, în anii 1924 și 1933, acesta a prezidat și Congresul Francez de Ortopedie DentoFacială (6-11).

Foarte importantă a fost și participarea medicului francez la organizarea Congresului de Stomatologie al Aliaţilor, care a avut loc în Paris, în perioada 9-13 noiembrie 1916. Cu această ocazie, au fost prezentate numeroase lucrări și conferințe referitoare la tratamentul multiplelor traumatisme din regiunea buco-maxilo-facială ale răniţilor de pe câmpurile de bătălie ale acestei mari conflagrații mondiale, precum și la protezarea defectelor osoase din aceste regiuni anatomice apărute la marii mutilați de război. Totodată, în zilele imediat următoare acestui mare congres, în intervalul 14-18 noiembrie, au fost vizitate foarte multe servicii de chirurgie buco-maxilo-facială, de protetică chirurgicală și de stomatologie și protetică clasică ale Armatelor Aliate aflate la acea vreme pe teritoriul francez (6-11). În paralel cu desfășurarea lucrărilor acestui impresionant congres de stomatologie, s-a desfăşurat și o grandioasă expoziţie de specialitate. Toate aceste evenimente s-au bucurat de un succes imens în rândul comunităţii medicale, civile și mi- litare, care activau în structura trupelor aliate. Toate materialele științifice prezentate au fost publicate abia în anul 1917 de către Profesorul Georges Villain și au însumat peste 600 de pagini și 1100 de figuri, acesta realizând un document de o importanță nemaiîntâlnită pentru acea perioadă (611).

Un rol deosebit 1-a avut Profesorul Georges Villain și în calitatea sa de mesager al lui Justin Godart, subsecretar de stat al Serviciilor de Sănătate ale armatei franceze între anii 1915 și 1918 (adică în timpul desfășurării primului război mondial). Concret, în calitate atât de profesionist stomatolog, dar şi de mesager al guvernului francez, Prof. Villain a contribuit într-un mod substanţial la definirea și organizarea serviciilor medicale de stomatologie ale armatei franceze în timpul războiului, dar a și participat la mai multe manifestări știinţifice profesionale extrem de importante:

- Congresul Asociației Engleze de Stomatologie din anul 1916, desfășurat în Anglia;

- Congresul Mixt al Societăților Canadiene și Americane de Stomatologie din luna iulie a anului 1918 desfăşurat în S.U.A.;

- Conferința Institutului American de Învățământ, conferință desfășurată în luna ianuarie 1919 în orașul american Atlanta (6-11).

Totodată, începând cu anul 1908, Profesorul Villain a participat la toate congresele Federației Dentare Internaţionale desfăşurate pe tot parcursul vieții sale, aducând o contribuție substanțială și la conducerea și organizarea acestei structuri profesionale și științifice, care există și în zilele noastre (6-11).

În continuare, se impune a discuta foarte pe scurt despre activitatea de auxiliar al Armatei Franceze în timpul Primului Război Mondial a Profesorului Georges Villain. Deși, era un cadru didactic superior extrem de apreciat în cadrul Școlii de Medicină Dentară din Paris, Profesorul Georges Villain a fost mobilizat în calitate de auxiliar în armata franceză, activând în cadrul regimentului 13 Artilerie Vincennes. Aici, reputatul medic francez a creat un serviciu de stomatologie extrem de eficient pentru acea vreme. Ulterior, Profesorul Villain a activat în cadrul serviciilor de stomatologie, care funcționau sub egida Şcolii de Medicină Dentară din Paris (6-11). Profesorul Georges Villain s-a implicat apoi în tot acel proces complex demarat și susținut de Justin Godart, subsecretar de stat al Serviciilor de Sănătate ale armatei franceze până în anul 1918, proces care a însemnat definirea și organizarea Serviciilor de Stomatologie în cadrul armatei franceze, atât în timpul, cât și după înche- 
ierea primului război mondial (1914-1918) (6-11).

Savantul francez s-a stins din viață în anul 1938, la vârsta de 57 de ani, într-un mod tragic, fiind victima unui accident de automobil (6-11).

\section{ALBÉRIC PONT (1870-1960)}

A fost un reputat medic dentist şi chirurg bucomaxilo-facial francez, considerat ca fiind fondatorul Centrului de Chirurgie Buco-Maxilo-Facială din Lyon, centru unde au fost tratați foarte mulţi soldați răniți pe câmpurile de bătălie din Franța, în timpul primului război mondial (1914-1918) (11-17).

Albéric Pont s-a născut pe data de 24 februarie 1870 în localitatea Bagnols-sur-Cèze, departamentul Gard, Franța, fiind singurul băiat dintre cei 7 frați (11-17). În luna iulie a anului 1888, la vârsta de 18 ani, reputatul medic dentist francez și-a susținut un prim bacalaureat la secțiunea filozofie, pentru ca, în luna noiembrie a aceluiaşi an, 1888, Albéric Pont să își susțină și un al doilea bacalaureat, de astă data la secțiunea științe, realizând astfel un lucru remarcabil pentru acele timpuri (11-17).

În continuare, Albéric Pont a devenit student în cadrul Facultăţii de Medicină din Lyon. În anul 1891, medicul francez a reușit al șaptelea la concursul de externat, pentru ca, 4 ani mai târziu, pe 12 octombrie 1895, Albéric Pont să reușească performanța de a promova un examen de internat de o dificultate deosebită, devenind intern al spitalelor din Lyon (11-17). Ajuns la acest moment, Albéric Pont a început cu adevărat să își pună problema ce specialitate va alege. Astfel, acesta a optat pentru stomatologie.

Claude Martin, un excelent medic dentist, dar în acelaşi timp şi un foarte bun prieten al lui Albéric Pont, a reuşit să îl convingă pe acesta să se specializeze în medicină dentară. Pont a acceptat și, astfel, după o specializare de 8 luni în cadrul Facultății de Stomatologie din Geneva, Elveția, Pont a devenit medic stomatolog (11-17).

După finalizarea acestei specializări în stomatologie, Albéric Pont s-a reîntors în orașul natal, Lyon, unde a practicat stomatologia, fiind în același timp și lector de medicină dentară în cadrul Facultății de Medicină din Lyon (11-17).

Dar, pe 12 decembrie 1899, șapte dentiști francezi (Pont, Ravet, Eugène Bonnaric, Jules Bonnaric, Pilois, Rouvier și Michaud) au înființat prima Școală de Medicină Dentară din Lyon, devenită ulterior Facultate de Medicină Dentară, prestigioasă instituție franceză de învățământ medical (11-17).

Încă de la înființare, această școală de stomatologie a fost recunoscută ca instituție de învățământ medical de stomatologie de către Asociaţia Dentiștilor din Franța (Association des Dentistes de France), în foarte scurt timp Dr. Albéric Pont devenind director al acestei școli, rămânând în această poziție până în anul 1943, într-o Franță ocupată la acel moment de către trupele germane ale lui Adolf Hitler. Totodată, Dr. Albéric Pont a fost, între anii 1937 și 1943, și președinte al Consiliului de Administrație al Școlii de Medicină Dentară din Lyon (11-17).

Tot Dr. Albéric Pont a fost cel care a înființat Societatea de Odontologie (Société Odontologique), organizând și prima conferință a acestei societăţi prestigioase, pe 10 mai 1900. Un deceniu mai tâziu, pe 15 ianuarie 1910, reputatul medic francez a înființat și jurnalul de stomatologie intitulat La Province Dentaire (11-17).

Începutul războiului îl găsește pe Dr. Alberic Pont voluntar în armata franceză, mai exact infirmier clasa a II-a în cadrul Gării Perrache. Concret, în urma Circularei nr. 14198 C/7 a guvernului francez (circulară emisă de către Justin Godart, 1871-1956, subsecretar de stat al Serviciilor de Sănătate ale armatei franceze în anii 1915-1918) din 10 noiembrie 1914 privind Organizarea Serviciilor Speciale de Stomatologie, de Protetică Maxilo-Facială și de Restaurare a Feței, circulară care a permis medicilor dentiști și tehnicienilor dentari încorporați în armata franceză să activeze în cadrul spitalelor de evacuare sau al spitalelor militare de campanie, în calitate de personal medical specializat în acordarea primului ajutor în cazul urgențelor stomatologice, precum și al răniţilor cu răni multilante din regiunea oro-maxilo-facială, Dr. Albéric Pont a înființat și a organizat Centrul de Chirurgie Buco-Maxilo-Facială din Lyon, care a căpătat denumirea de Spitalul Complementar nr. 19, unde acesta a activat alături de cadrele didactice ale Școlii de Medicină Dentară din Lyon. Tot în cadrul acestui renumit centru de chirurgie buco-maxilofacială, a funcționat pe toată durata desfășurării războiului și unul dintre cele mai performante laboratoare de realizare a protezelor chirurgicale din Franța (11-17).

Într-o primă etapă, Dr. Albéric Pont și colaboratorii săi au activat ca asociați civili ai armatei franceze, dar, începând cu data de 7 aprilie 1916, aceștia au fost recunoscuți ca militari și ofițeri ai aceleiași armate franceze, munca depusă de aceștia în cadrul Centrului de Chirurgie Maxilo-Facială din Lyon fiind una extrem de apreciată de către autorităţile civile şi militare.

Dr. Albéric Pont și colaboratorii săi au tratat pe toată durata ostilităților primului război mondial 
peste 7000 de soldați răniți în regiunea buco-maxilo-facială, realizând, în acelaşi timp, și un număr considerabil de proteze chirurgicale pentru mutilații de război (11-17).

Datorită meritelor sale excepționale pe tărâm medical, tot în anul 1916, Albéric Pont a fost distins cu Premiul Claude Martin din partea Academiei Franceze de Medicină, pentru ca, un an mai târziu, acesta să devină Cavaler al Legiunii de Onoare, cea mai înaltă distincție franceză (11-17).

Astfel, pe toată durata conflictului, Dr. Alberic Pont a fost șeful Centrului de Chirurgie BucoMaxilo-Facială al Regiunii Militare XIV Lyon, rămânând în această poziție până la demobilizare, în anul 1919 (11-17).

După încheierea Marelui Război, Dr. Alberic Pont și-a reluat activitatea didactică și clinică întreruptă de luptele încrâncenate duse pe teritoriul Franței (11-17).

Totodată, în perioda interbelică, alături de funcția de director, dar şi de președinte al Consiliului de Administraţie al Facultăţii de Stomatologie din Lyon, Dr. Alberic Pont a deținut și alte funcții administrative în sistemul de sănătate din orașul Lyon, cum ar fi cea de administrator al Ospiciilor Civile din Lyon (între 3 martie 1937 și 20 august 1941).

În paralel, reputatul medic francez a avut și o activitate științifică cu adevărat remarcabilă, participând la un mare număr de congrese și conferințe de specialitate atât în Franța, cât și în afara ei (Congresul Interaliat al Mutilaților de Război din anul 1918, desfășurat la Roma; Congresul de Stomatologie desfășurat în anul 1936 la Paris, congres pe care 1-a și prezidat) (11-17).

În timpul ocupației germane a Franței din al doilea război mondial, la rugămintea aceluiași Justin Godart, subsecretar de stat al Serviciilor de Sănătate ale armatei franceze în timpul primului război mondial, Dr. Alberic Pont a înființat și a gestionat în clandestinitate o școală de tehnicieni dentari, care și-a desfăşurat activitatea pentru Rezistența franceză (11-17).

Începând cu data de 1 februarie 1950, Dr. Albéric Pont a fost numit președinte al Consiliului Ospiciilor Civile din Lyon, post pe care acesta 1-a deținut până în anul 1952, când a devenit președinte de onoare al aceluiași consiliu (11-17).

Pe 20 aprilie 1959, marele medic francez a demisionat din toate funcțiile administrative pe care le deținea, pentru ca, pe 2 februarie 1960, să se stingă din viață la vârsta de 90 de ani (11-17).

În ceea ce privește activitatea științifică și de cercetare a marelui savant francez, aceasta a fost, într-adevăr, una de excepție. Concret, acesta a scris și a publicat în perioada 1897-1937 aproximativ 115 articole, dintre care 9 pe parcursul desfășurării primului război mondial (1914-1918) (11-17):

- Prothèse nasale. Lyon Médical (1914);

- Trousse d'urgence pour l'immobilité immédiate des fractures du maxillaire în anul (1915);

- Traitement immédiat des fractures du maxillaire inférieur vicieusement consolidée. C.I.A. (1916);

- Indications et technique de la greffe osseuse dans les pseudarthroses du maxillaire inférieur. C.I.A. (1916);

- Modifications apportées à l'arc d'Angle dans la réduction et la contention des fractures. C.I.A. (1916);

- Thérapeutique du tissu cicatriciel consécutif aux blessures de guerre. C.I.A. (1916);

- Rhinoplastie et prothèse nasale. Société Médicale et Chirurgicale de la XIV-ème Région (1917);

- Chirurgie plastique et prothèse auriculaire (1918);

- Prothèse des grands blessés de la face et des maxillaires. Congrès des Mutilés de Guerre, Roma (1918).

Totodată, reputatul chirurg buco-maxilo-facial francez a fost și autor a 2 cărți de referință pentru medicina stomatologică din Franța:

- Précis des maladies de la bouche (1921);

- L'orthodontie dans la pratique courante (1928) (11-17).

\section{EMILE-JULES MOURE (1855-1941)}

Un alt medic francez, reputat specialist O.R.L., care a avut o contribuție deosebită la tratarea soldaților răniţi în timpul primului război mondial pe frontul de vest (frontul francez), a fost EmileJules Moure (11,18-20). S-a născut în orașul Bordeaux în anul 1855. După ce a studiat medicina în capitala Franței, Paris, Dr. Emile-Jules Moure s-a specializat în otorinolaringologie atât în Franța, cât și ulterior în Germania, Austria (țară care la acea vreme se afla în componența Imperiului AustroUngar), Rusia și Marea Britanie (11,18-20).

În anul 1880, reputatul medic francez a revenit în orașul natal, Bordeaux, unde a deschis prima clinică de O.R.L. (otorinolaringologie) din Franța (Clinique Saint-Augustin) (11,18-20).

Tot în același an, 1880, Dr. Emil-Jules Moure a înființat și prima revistă de specialitate din Franța, revistă intitulată Revue Mensuelle de Laryngolo- 
gie, d'Otologie et de Rhinologie, contribuind în mod decisiv la afirmarea acestei specialități ca disciplină medicală distinctă nu doar în Franța, ci în întreaga Europă $(11,18-20)$. Astfel, începând cu anul 1891, reputatul medic francez a devenit lector pe specialitatea O.R.L., ajungând în anul 1913 primul cadru didactic universitar din Franța cu grad superior al acestei specialități medicale, otorinolaringologia, respectiv profesor universitar cu drepturi depline în cadrul Facultății de Medicină din Bordeaux, Franța. Totodată, în anul 1892, EmilJules Moure a contribuit la înființarea Societății Franceze de O.R.L. (Société Française d'Otologie et de Laryngologie), devenind în anul 1889 și președinte al acestei prestigioase societăți medicale franceze $(11,18-20)$.

În anul 1895, Dr. Emil-Jules Moure a publicat în premieră primul tratat de otorinolaringologie din Franța, tratat intitulat Traité pratique des maladies des fosses nasales, de la cavité naso-pharyngienne et des sinus de la face (Tratat practic al afecțiunilor foselor nazale, al cavității nazo-farinigiene și al sinusurilor feței), material de referință pentru O.R.L., aflată la acel moment în Franța întro fază de pionierat (11,18-20).

Odată cu izbucnirea primului război mondial în anul 1914, Dr. Emil-Jules Moure a dirijat serviciul O.R.L. din cadrul Spitalului Temporar nr. 25 din Talence, precum și Serviciul pentru Consultații O.R.L. din cadrul Spitalului Saint-André, pentru ca, începând cu luna octombrie a anului 1917, să devină șeful Centrului de Chirugie Buco-MaxiloFacială din Bordeaux, centru aflat în cadrul Regiunii XIII Militară din Franța (11,18-20).

După încheierea ostilităţilor războiului, în anul 1918, reputatul medic francez și-a continuat activitatea medicală în orașul natal, Bordeaux. Dar, la finalul unei cariere extrem de prodigioase, marele savant francez a dorit să își desemneze și un succesor în profesie. Acesta a fost nimeni altul decât ginerele său, Dr. Georges Portmann (1890-1985) (s-a căsăstorit cu fiica lui Emil-Jules Moure în anul 1918), excelent specialist O.R.L., care a devenit șef de clinică în anul 1920, profesor agregat (asociat) în anul 1923 și profesor universitar cu drepturi depline de O.R.L. în cadrul Facultății de Medicină din Bordeaux, în anul 1926 (11,18-20).

În anul 1930, Dr. Moure a scris și o istorie a Societăţii Franceze de O.R.L. (Société Française d'Otologie et de Laryngology). Reputatul om de știință francez s-a stins din viață în anul 1941, în plină desfășurare a celui de-al doilea război mondial $(11,18-20)$.

\section{HIPPOLYTE MORESTIN (1869-1919)}

A fost un important medic francez, după unele surse bibliografice profesor agregat, după alte surse bibliografice profesor universitar cu drepturi depline de anatomie în cadrul Facultății de Medicină din Paris, reputat specialist în chirurgie plastică și reparatorie, care și-a adus o contribuție remarcabilă în tratamentul și apoi în recuperarea marilor mutilați de pe câmpurile de bătălie din Franța în timpul primului război mondial (1914-1918), având un rol deosebit în definirea chirurgiei bucomaxilo-faciale ca specialitate medicală de război (11,21-28).

Reputatul medic francez s-a născut pe data de 1 septembrie 1869 în localitatea Basse-Pointe, Martinica, Antilele Franceze, fiind fiul unuia dintre respectații medici locali, mort în anul 1902, în urma unei puternice erupții vulcanice, care a făcut peste 25.000 de victime în rândul localnicilor (11,21-28).

În perioada premergătoare războiului, Hippolyte Morestin a avut o activitate clinică extrem de diversificată, fiind interesat în mod deosebit de afecțiunile buco-maxilo-faciale și în special de formațiunile tumorale cu localizare la nivelul limbii și al planşeului bucal. În acest sens, marele chirurg francez a imaginat o serie de intervenții chirurgicale foarte variate, inițial bazându-se pe un tratament cât mai conservativ, pentru ca, ulterior, acesta să devină adeptul rezecțiilor cât mai radicale ale formațiunilor anatomice afectate de către aceste formațiuni maligne (11,21-28).

În paralel cu activitatea clinică, Dr. Hippolyte Morestin a avut și o activitate didactică bogată în cadrul Facultății de Medicină din Paris, fiind profesor agregat al acestei importante instituții de învăţământ medical superior din capitala Franței (11,21-28).

Izbucnirea războiului 1-a găsit pe excepționalul medic francez, considerat a fi unul dintre întemeietorii chirurgiei buco-maxilo-faciale din Franța și, totodată, unul dintre primii specialiști care a definit această disciplină ca fiind o specialitate medicală de război (sau conflict), întâi ca șef al Serviciului de O.R.L. din cadrul Spitalului Saint-Louis din Paris, dar și ca specialist în chirurgie buco-maxilo-facială în cadrul Spitalului Val-de-Grâce, spital aflat tot în capitala Franței (11,21-28).

Totodată, Dr. Hippolyte Morestin a organizat și un foarte eficient serviciu de chirurgie buco-maxilo-facială, serviciu care aparținea de armata franceză, unde a tratat foarte mulți răniţi, mutilați de război, de pe câmpurile de bătălie din Franța. 
În perioada 14 martie 1914 - 30 octombrie 1918, reputatul chirurg francez a publicat în Bulletins et Mémoires de la Société de Chirurgie de Paris peste 45 de articole privind intervențiile de reconstructiie buco-maxilo-faciale, materiale științifice care studiau în detaliu toate aceste aspecte dramatice ale marilor mutilaţi de război. Tot în anul 1918, Dr. Hippolyte Morestin a publicat și o carte considerată de referință pentru specialitatea de chirurgie buco-maxilo-facială, carte intitulată Les blessures de la face (11,21-28).

Trebuie menționat faptul că, la începutul anului 1914, exact înaintea izbucnirii acestei prime mari conflagrații mondiale, reputatul savant francez a participat la Congresul Internațional de Chirurgie desfășurat la New York, S.U.A., eveniment de o importanță extraordinară pentru comunitatea medicală și academică a acelei perioade $(11,21-28)$.

În luna iunie a anului 1915, Dr. Hippolyte Morestin a avut, pentru o scurtă perioadă de timp, o colaborare interesantă cu marele chirurg bucomaxilo-facial englez Sir Harold Delf Gillies (18821960) (11,21-28).

Totuşi, se pare că, în ultimii ani de conflict, Dr. Hippolyte Morestin, conștient fiind de pregătirea sa extraordinară ca specialist în chirurgia bucomaxilo-facială și în chirurgia plastică și reconstructivă, a refuzat să mai colaboreze cu colegii săi dentiști, pornind împotriva acestora o campanie de denigrare foarte agresivă. Finalul războiului l-a găsit pe Dr. Hippolyte Morestin în plină glorie: o delegație a mutilaților de război tratați de către acesta făcând parte din suita primului ministru francez Georges Clemenceau (1841-1929), a participat la Tratatul de la Versailles, tratat semnat pe

Conflict of interest: none declared

Financial support: none declared

\section{BIBLIOGRAFIE}

1. Oprea HD. Primul Război Mondial (prima parte). Istorii regăsite. Available at: https://istoriiregasite.wordpress.com/2013/11/29/ primul-razboi-mondial-prima-parte/.

2. Muzeul Național de Istorie a României. Prima pagină. Marele război. Available at: http://www.marelerazboi.ro/.

3. Wikipedia. Primul Război Mondial. Wikipedia.org. Available at: https:// ro.wikipedia.org/wiki/Primul_R\%C4\%83zboi_Mondial.

4. Historia. Cum a decis Franța soarta războiului în august 1914. Available at: https://www.historia.ro/sectiune/general/articol/ cum-a-decis-franta-soarta-razboiului-in-august-1914.

5. Wikipedia. Frontul de vest (Primul Război Mondial). Wikipedia.org. Available at: https://ro.wikipedia.org/wiki/Frontul_de_vest_ (Primul_R\%C4\%83zboi_Mondial).

6. Georges Villain, Paris, France. J Am Dent Assoc. 1931;18(3):ii

7. Riaud X. Hommage à l'action de Georges Villain (1881-1938), professeur à l'Ecole dentaire de Paris, pendant la Grande Guerre 2012, Verdun-meuse.fr. Available at: http://verdun-meuse.fr/index. php?qs=fr/ressources/hommage-a-laction-de-georgesvillain-(1881-1938) data 28 iunie 1919 şi care a însemnat de fapt sfârşitulul războiului (11,21-28).

Dr. Hippolyte Morestin nu a apucat să se bucure de această glorie; epidemia de gripă spaniolă din Europa de la acest final de război avea să mai facă încă o victimă în persoana excelentului chirug francez, acesta stingându-se din viață pe 12 februarie 1919, la Paris (11,21-28).

\section{CONCLUZII}

În timpul primului război mondial, asupra serviciilor medicale franceze, atât civile, cât și militare, presiunea acestor confruntări desfășurate pe teritoriul naţional a fost cu adevărat fantastică. Tot ceea ce a însemnat practician cu o pregătire medicală mai mult sau mai puțin aprofundată (medici, asistenți medicali, infirmieri etc.) a fost implicat în îngrijirea răniților de pe fronturile unde trupele franceze efectiv luptau contra armatelor Puterilor Centrale. Tot în această categorie a personalului medical au intrat și cei care practicau medicina dentară: medici stomatologi, asistenți medicali de stomatologie, tehnicieni dentari. Iar Georges Villain, Albéric Pont, Emile-Jules Moure, Hippolyte Morestin au fost printre cele mai cunoscute nume din Franța, medici și/sau cu specialități din sfera oromaxilo-facială care au desfășurat o activitate remarcabilă de îngrijire a rănților în spitalele franceze în timpul primului război mondial (1914-1918).

\section{Notă}

Toți autorii au avut contribuții egale cu cea a primului autor.

8. Riaud X. 1916: An I du dentiste militaire en France, Verdun-meuse.fr. Available at: http://verdun-meuse.fr/index.php?qs=fr/ ressources/1916-an-i-du-dentiste-militaire-en-france.

9. Riaud X, Tribute to Georges Villain (1881-1938), Professor at the Dental School of Paris, During the Great War. J Dent Probl Solut. 2015;2(1):008-014.

10. Riaud X. Charles Godon (1854-1923) et Georges Villain (1881-1923), le maître el l'élève (Médecine à travers les siècles). Paris: Ed. L'Harmattan, 2018.

11. Burlibașa M, Dumitru SG, Costea R, et al. Serviciile medicale de stomatologie din cadrul armatelor combatante în timpul Primului Război Mondial (1914-1918). În: Burcea CC, Dumitru SG, Costea R et al. Probleme în medicină și biologie, Vol. VII, București: Ed. Ars Docendi, 2017:19-123.

12. Albéric Pont. Wikipédia.fr. Available at: https://fr.wikipedia.org/wiki/ Alb\%C3\%A9ric_Pont.

13. Riaud X, Le docteur Albéric Pont (1870-1960), chirurgien-dentiste, médecin et créateur du centre de chirurgie maxillo-faciale de Lyon en 
1914, Verdun-meuse.fr. Available at: http://verdun-meuse.fr/index. php?qs=fr/ressources/le-docteur-alberic-pont-\%281870-1960\%29.

14. Clinique du docteur Albéric Pont. Atelier-histoire.ens-lyon.fr. Available at: http://atelier-histoire.ens-lyon.fr/AtelierHistoire/episodes/view/162.

15. Riaud X. Doctor Albéric Pont (1870-1960). Dental surgeon, doctor and creator of the center of maxillo-facial surgery of Lyon in 1914. Hist Sci Med. 2008;42(3):317-322.

16. Wikipédia. Albéric Pont. Wikiwand.com/fr. Available at: http://www. wikiwand.com/fr/Alb\%C3\%A9ric_Pont.

17. Sigaux N, Amiel M, Piotrovitch d'Orlik S, Breton P. Alberic Pont, the great war and the "broken faces". Ann Chir Plast Esthet. 2017;62(6):601-608.

18. Émile-Jules Moure. Fr.widipedia.org. Available at: https://fr.wikipedia. org/wiki/\%C3\%89mile-Jules_Moure

19. Riaud X, Emile-Jules Moure (1855-1941). Histoire-medecine.fr. Available at: http://www.histoire-medecine.fr/premiere-guerremondiale/emile-moure.pdf.

20. Medicine Émile-Jules Moure / otolaryngologist / French bronze medal. Worthpoint.com. Available at: http://www.worthpoint.com/ worthopedia/medicine-emile-jules-moure-313890394.
21. Hippolyte Morestin. Wikipedia.org. Available at: https://www.en. wikipedia.org/wiki/Hippolyte_Morestin.

22. Lalardrie JP. Hippolyte Morestin 1869-1918. Br J Plast Surg. 1972;25(1):39-41.

23. Benmoussa N, Fanous A, Charlier P. Jane Poupelet (1874-1932): A women artist devoted to the wounded soldiers from the First World War. J Stomatol Oral Maxillofac Surg. 2020;121(3):325-326.

24. Derquenne F. Two French pioneers of plastic surgery: François Dubois and Raymond Passot. Hist Sci Med. 2015;49(1):29-40.

25. Chevallier X. Le destin hors du commun du docteur Hippolyte Morestin. Available at: https://www.madinin-art.net/le-destin-hors-ducommun-du-docteur-hippolyte-morestin/.

26. Rogers BO. Hippolyte Morestin (1869-1919). Part I: A brief biography. Aesthetic Plast Surg. 1982;6(3):141-147.

27. Mazzola RF, Mazzola IC. Fat Grafting in the Management of War Injuries. J Craniofac Surg. 2019;30(3):678-681.

28. Benmoussa N, Hansen K, Charlier P. Use of Fat Grafts in Facial Reconstruction on the Wounded Soldiers From the First World War (WWI) by Hippolyte Morestin (1869-1919). Ann Plast Surg. 2017;79(5):420-422. 